\title{
Commentary
}

\author{
Mark Sebba
}

Department of Linguistics, Lancaster University

Is language more like friendship or a table? I sometimes ask my postgraduate classes this and although they give the right answer - friendship - it is annoyingly true that most of the time, we - that is linguists, myself included - find it easier to think of language(s) as something concrete, bounded, and with fixed characteristics. This 'furniture thinking' is probably an even more convenient and compelling trap to fall into when considering specifically written language, since writing has a visible image and can be perceived to inhabit physical space in a way which spoken language does not.

Extracting ourselves from this long-existing trap has become a theme for many researchers in sociolinguistics and related disciplines in recent years. One outcome has been the proliferation of 'novel terms and paradigms' as discussed by Adam Jaworski (this issue), also termed the 'trans-super-poly-metro movement' (Pennycook, 2016). Movement or not, it is clear that sociolinguistics has taken a turn in a direction away from the 'reification and totemisation' of languages which researchers like Le Page and Tabouret-Keller (1985) drew attention to decades ago. All the papers in this issue testify to that. In this short commentary, I will try to draw together some of the most interesting points from the diverse papers collected here. I will not attempt to comment on their conclusions or to find a common theme in all of 
them, but will look at what I think are some of the key ideas which emerge from the theories and the data presented.

In her paper, Friederike Lüpke points out how the proponents of translanguaging theory, Li Wei among them, have argued that 'multilingual' practices have often been identified using an external viewpoint, which is based on 'socially grounded reification processes paying disproportional attention to language as the only semiotic means'. Meanwhile the reality perceived by the language users is different, reflecting how their practices 'transcend bounded codes in ways that diminish the prominence of language as the foremost semiotic tool'. For the papers in this issue, that assumption of language being the primary or only semiotic tool has largely been abandoned, though the nature and importance of the other semiotic tools involved, and their relationship with language, differs from case to case. Jaworski puts it thus: 'linguistic resources combined with other modes [...] carry multiple indexicalities, subject positions, categorizations, narratives, affective interactions and responses, to name but a few.'. In other words, the modalities of language remain the focus, but are by no means the only source of meaning. The interplay - give and take, action and reaction, association and connotation - between language and the non-linguistic environment, broadly interpreted, is essential to the interpretation of the linguistic act at the centre.

The desire to avoid the trap of 'furniture thinking,' i.e. to avoid reifying and compartmentalising language, enhances and complements two other developments which are highlighted in the papers here. The first is the recognition of the importance of other modalities, especially the visual, and analytic categories including layout and composition, which (as Jaworski points out) have been discussed by multimodality scholars for 30 years or so but are still seen as rather marginal in linguistics. The second development is the move away from another longstanding trap which linguists have tended to fall into, namely a focus 
on the 'serious' functions of language (particularly its informative and persuasive uses) at the expense of the playful or ludic functions. Whether it is because the appearance of the internet has made these playful functions more widespread or more visible, or whether it is simply that researchers have decided that there is a lot going on that deserves more serious consideration, it is clear that much more attention is being given to linguistic practices which are 'fun', even when they may have a more serious (e.g. political) purpose.

The written practices discussed in this issue vary from highly individual to generic. At one end of the spectrum we have the individualised 'minimal texts' which Jaworski writes about, each a semiotic assemblage unlike any other, although possibly belonging to a recognizable genre like ‘birthday card' or 'shop sign'. Hellenised English has 'a certain public reach and social recognition' (Androutsopoulos, this issue) but is nonetheless a minority practice. 'Kongish' at the moment seems likewise to be confined to a minority though with potential to expand ( $\mathrm{Li}$ Wei et al., this issue). At the other end of the scale we have readily recognized generic practices like displaying public signage and note-taking in Swedish companies (Jonsson \& Blåsjö, this issue): it is their multilingual/translanguaging character that makes them of interest here.

Looking first at the more individualised practices, Adam Jaworski's Polish "dressed up" as Chinese and Jannis Androutsopoulos's English dressed as Greek could be seen as related phenomena. Though for very different purposes, both invite 'viewers to gaze on visual linguistic forms' (Androutsopoulos, this issue) and through them to make an interpretation of the linguistic content. A crucial difference is that the 'Chinese' restaurant signs are merely made to resemble the reader's supposed perception or stereotype of Chinese characters, while Hellenised English is written in real Greek letters which are well known to the readers. In both cases the reader is invited to experience one language through the appearance of another. In the case of Hellenised English the effect is intentionally humorous 
or mocking, in the other less so, but still from the 'fun' end of the range of functions.

Necessarily, 'Chinese' signs in Jaworski's paper are not really Chinese, as they would not be comprehensible to the intended readership if they were. The expected readers of these signs are aware of this, of course, but can agree that the letters have been stylised and/or exoticised to evoke Chinese characters.

A characteristic of much of the (trans)languaging discussed in this issue is the way it involves multiple levels of interpretation involving multiple linguistic systems. Hellenised English, for example, requires 'English' to be read via the Greek alphabet. The reader can produce a 'sounding' on the basis of the Greek letters, but only the realisation that this is actually 'English' rather than the expected Greek will make it understandable. But that in itself is not enough, because resegmented strings and spelling puns only produce humour if they are recognized as both Greek and English, meaning that both English and Greek are constantly 'in play', with the reader/hearer having to recalculate constantly which language(s) to use as an interpretive frame. Such multi-level complexity has sometimes been observed in other contexts, for example in graffiti. Romiti (1998, p. 290) describes contemporary Roman graffiti where the numeral $<1>$ must be 'read as English' but pronounced as Italian, thus $<$ NAS1 $>$ is to be read NASONE, pronounced [na'zone], 'one with a big nose'. The reading $\langle 1\rangle=\langle\mathrm{ONE}\rangle$ in this context has probably become conventionalised, but readers must still decide whether it should be given an Italian reading (producing 'Nasuno', which is meaningless in context) or an English one (see Sebba, 2007, pp. 40-41). The English/Chinese bilingual youths studied by Li Wei (2011) made frequent use of spoken multilingual wordplay, sometimes with an element relating to written language. For example, a person whose Cantonese name was pronounced as bakkin was referred to as $\mathrm{MD}$, because the young men 'thought it sounded like the English word barking and extended it to barking mad, hence mad dog, which was then shortened as MD' (Li Wei, 2011, p. 1226). Similar complex 
wordplays, involving elements of Chinese and Roman script, English, Cantonese, Mandarin and Japanese seem to be the norm in the Kongish Daily Facebook page (Li Wei et al., this issue).

Even complex 'rescripting' as in the case of Hellenised English is not entirely new. For example, the 1972 publication Ah Big Yaws?: A Guard to Sow Theffricun Innglissh ("I beg yours? A Guide to South African English") (Malan, 1972) displays many of the same strategies for 'transsscripting' Standard English into South African English without actually changing script. Instead, respellings, sometimes phonetically motivated (<guard $>=$ [ga:d]) and sometimes 'eye-dialect' ( $<$ Ingglissh $>$ ) and other devices like resegmentation $(<$ Sow Theffricun>) and spelling puns (<yaws> for 'yours') construct a stance of gentle mockery towards this language variety, which is native to the majority of South Africans of European descent whose first language is English ${ }^{1}$. The medium is different, of course, as is the purpose, which is not political but only humorous - although it is just as much the product of language ideologies (in this case, about the 'inferiority' of South African English compared to British English.) In the case of Hellenised English, the Greek alphabet provides a readymade way of associating English words with a Greek pronunciation. In respelling English to represent South African English, a similar effect is achieved by using English orthography in unexpected ways: as in the case of Hellenised English, the main function of the re-scripting is 'not to assist propositional understanding, but to construct the evaluation' of the speech represented (Androutsopoulos, this issue). So there are many similarities between the internet-era phenomenon of Hellenised English and this pre-internet form of linguistic playfulness.

Multilingual wordplay involving video subtitles has been observed elsewhere on the internet. The practice of 'buffalaxing' (Leppänen \& Häkkinen, 2012) also involves the addition of subtitles, in this case to a clip of a foreign-language film or video, in such a way 
that the original words (say, in Hindi-Urdu) are intentionally 'misheard' as words in a different language (such as English or Finnish). The subtitles thus misrepresent the original, usually with comic effect (often by 'mishearing' them as overtly sexual when they were not, thereby creating innuendo). Thus 'a new video is created, with new meanings generated not only via the subtitles but also through their co-occurrence and juxtaposition with the original image and audio' (Leppänen \& Häkkinen, 2012, p. 17). As in the case of Hellenised English subtitling, this is a multimodal languaging practice involving written language, carried out with humorous or parodic intentions. Meanwhile in Kongish Daily (Li Wei et al., this issue) much of the humour seems to be based around the retranscription of 'monolingual' texts from English, Chinese or Japanese into the hybrid, apparently anarchic, Kongish. This is clear, for example, in the ironic other-language subtitling of video clips, whose purpose is clearly 'not to assist propositional understanding' but to get laughs.

Of course, even in 1972 it was possible in theory to subtitle a film with captions in mock South African English. What is new is the ease with which it can now be done, and who has the capability to do it. Until quite recently, subtitling involved specialised equipment which was only available at some expense and to those who had the required expertise to use it. Few people could afford to subtitle a film just for fun, and if they did so not many were likely to see it. Thus while the potential was there for 'rescripting' or 'transscripting', the scale of the phenomenon was likely to be limited. The internet and the accompanying technologies of hardware and software have made it easier for people to create and disseminate transscripted videos on a relatively large scale. The affordances of the internet seem to have created the conditions for translanguaging wordplay to be disseminated more widely, whether the practices concerned require specialised competence (like Hellenised English) or are more generic. 
Turning to the more generic end of the spectrum, we find the practices described in the paper by Carla Jonsson and Mona Blåsjö and the paper by Friederike Lüpke. Looking at these, it seems that in some respects multilingualism can be quite similar to monolingualism. If we casually glance over the handwritten notes made by 'Richard' at a seminar(Jonsson and Blåsjö, this issue), we see a set of notes in the form of short texts structured by 'bullets', circles, underlining, asterisks and arrows. The only remarkable thing about it - if it is remarkable - is that on closer inspection, some of the text is in English and some in Swedish. There are no clear visual boundaries between the two languages; though the 'bullet point' texts tend to be either all in Swedish or all in English, the second asterisk point starts in Swedish, switches to English, then switches back. As the authors show, there are some differences in how and where English and Swedish are used to report the symposium content. 'Richard' has also added some annotations in Swedish which are not derived from the presentation itself, but are to help him navigate his notes: '(se iPhone-bild)' where the text in brackets is an indication to look at the photo of the screen which is on his phone. We have here a text that conforms to the expectations of the genre 'handwritten notes on a presentation' at the same time as it breaks the monolingual norm. So what is happening here? Are expectations of monolingualism in writing in fact genre-dependent, strongest in the most regulated domains of writing, but weak when it comes to informal activities like note-taking?

My point is that this is very similar to a text with a similar purpose that could have been produced by a monolingual, a person with similar literacies and competences who just happened to know only one (standard, written) language. Though it is in fact the work of an individual who is competent and confident in two written languages, a very similar text could have been the work of a monolingual, or even a multilingual who chose to write in just one language. Unlike some of the multilingual writing described in this volume, it does not draw attention to its multilingualism, nor does it depend for effect or effectiveness on the sort of 
complex language-based semiosis that is required, for example to interpret trans-scripted subtitles in Hellenised English.

Different and yet not-so-different is the shop sign from Mali which is discussed in Friederike Lüpke's paper. This sign consists of just three lines of text (with a phone number below):

\section{QUINCAILLERIE MINIANKALA}

CHEZ ALMAMY TRAORE

ALLAH KA TJINE DEME KAW YERE KE A DEME BAKAYE

To an analytically-minded linguist, there are elements of both French and Bambara here, but to the local lay reader, this text is language-independent writing which 'instantiates (trans)languaging, since elements that can be attributed to different languages are not systematically differentiated nor set apart typographically' (Lüpke, this issue). Rather, as in the hand-written symposium notes, the conventions of the shop sign genre are upheld as different semiotic functions of the text,indicated by font size, colour and placement. At the same time normative considerations of monolingualism are disregarded as the languages are not systematically distinguished.

In both cases it seems significant how the role of visual features - the spatial organisation, colours, font, letter size and the presence of non-linguistic signs such as arrows and lines (in the case of the handwritten notes) outweighs any organisational role which code choice (i.e. the specific language employed in a stretch of text) might play. Lüpke describes the Malian text as not only (trans)languaging, but an example of language-independent writing which 'remains agnostic to categorising all of its elements in terms of language(s) contained $[\ldots]$ thus offering a radically different perspective on texts that are commonly classified as multilingual but are not necessarily so for their writers and readers'. It seems 
reasonable to ask whether the same could be applied to the handwritten symposium notes, which to the external viewer with a language-based mindset, consists of a mixture of English and Swedish text. Yet English and Swedish start out with a similar alphabet and many shared features of orthography. In that sense the transitions from English to Swedish and vice versa are 'seamless', unmarked by any specific features of orthography or script. So is 'Richard' engaged in a practice of 'language-independent writing'? In answering such a question about any text, questions of potentially multiple internal and external perspectives, resources, affordances, and the historical body of the writer and reader come into focus. In this case, it seems highly likely that 'Richard' has been schooled in the standard, dominant written forms of both English and Swedish and has internalised an essentially monolingual view of what they are. He would probably agree with a hypothetical external analyst that he has written in a mixture of these two languages, breaking for pragmatic reasons with the convention of writing strictly in one or the other. Being competent in the academic forms of both, he could probably write up a report of the event for circulation around his office in either language, but would not break the conventions to the extent of writing a formal document in a mixture.

Reviewing the range of practices described in this issue, it looks as though some involve much more reflexivity -language 'drawing attention to itself' as Androutsopoulos puts it - than others. While all the practices discussed involve an interplay of languages, along with the 'other symbolic and material resources' mentioned by Jaworski, some of them seem to require an enhanced engagement with language itself, including some degree of conscious 'language work'. Arguably, the ability to do this is just part of being human - Normann Jørgensen makes this point: 
Language users language with all their skills and knowledge which may involve detailed knowledge [...] or very little [...] The behaviour is fundamentally the same, we are all languagers. (Jørgensen, 2008, p.169)

But not all linguistic activity, even translanguaging, requires this level of attention. It seems that all of us can play word games, or communicate via language-related puzzles, if we choose to; but equally, we don't have to. Just for fun I could send a text message to a friend, who I suspect may be abroad on a summer holiday, as follows:

$\mathrm{u}$

cccce?

Assuming the fictitious friend makes precisely the correct assumptions in order to achieve a reading - that, despite the use of the letter $<u>$ as an abbreviation of 'you' which is common in SMS messages, the complete message is actually a rebus, involving both language and spatial relations, in which the sequence of letters $\langle\mathrm{c}\rangle$ should be read as a plural of $\langle\mathrm{c}\rangle$, i.e. /si:z/ - they will derive the meaning, 'You overseas?'. To this they might respond $\mathrm{cc}$

which could be understood - again, only by making some very specific assumptions, namely that in this case each individual $<c>$ is to be given its English name, but interpreted as a word of Spanish - as sí sí, thereby also giving a clue to their whereabouts.

This exchange, you might think, is potentially an amusing diversion, and shows what we can do with language, even in small quantities, when we come out with all modalities blazing. We are all languagers. But most communications do not require this degree of 
complex activation of different modes and linguistic subsystems - and with good reason. Most of us don't want to solve a multilingual puzzle each time we have a conversation, even if it is within our cognitive capabilities to do so. We tend to fall into more conventionalised patterns of behaviour, keeping to existing genres, though from time to time we create a new one. Certainly, the internet and digital technologies have opened up some new spaces for this.

So, to return to the beginning, is language like a table or like friendship? Perhaps what we can learn from these papers will give rise to the 'table-friendship theory of language' (after all, we have wave-particle theory...). Language is, of course, not a concrete thing but, just as actors in a minimalist play can 'create' a table on a bare stage by behaving as though it is there, we can and do behave as though written language has some concrete properties. This imaginary table, if it behaves like a thing, is certainly a flexible one, which can fold up, extend, and be a table for a bistro or a banquet: it can blend seamlessly with other tables but also be self-consciously heterogenous, repurposed as something different. At the same time, it behaves as a concept, a product of the collective imagination and some clever acting, and this lack of concreteness makes it possible to transform it in different ways using the whole range of semiotic tools. What the papers in this special issue show is the great variety of 'trans-super-poly-metro-' languaging practices which we humans engage in, as we begin to shed light on the nature of multilingual writing.

\section{Acknowledgements}

Thanks to the reviewers for their helpful comments and suggestions. 


\section{References}

Jørgensen, J. N. (2008). Polylingual Languaging Around and Among Children and Adolescents. International Journal of Multilingualism, 5(3), 161-76

Le Page, R.B. \& Tabouret-Keller, A. (1985). Acts of Identity. Cambridge University Press.

Leppänen, S., \& Häkkinen, A. (2012). Buffalaxed superdiversity: representations of the other on YouTube. Diversities, 14(2), 17-33, UNESCO. ISSN 2079-6595

www.unesco.org/shs/diversities/vol14/issue2/art2

Li Wei (2011). Moment analysis and translanguaging space: Discursive construction of identities by multilingual Chinese youth in Britain. Journal of Pragmatics, 43, 1222-1235.

Malan, R. (1972). Ah Big Yaws?: A Guard to Sow Theffricun Innglissh. David Philip.

Pennycook, A. (2016). Mobile times, mobile terms: The trans-super-poly-metro movement. In N. Coupland (ed.), Sociolinguistics: Theoretical Debates (pp. 201-216). Cambridge University Press.

Scollon, R. \& Scollon, S. W. (2004). Nexus Analysis: Discourse and the Emerging Internet. Routledge

\footnotetext{
${ }^{1}$ Another example: Whoozzat Ahsore ewewirth lar snart? = 'Who's that I saw you with last night?' (Malan 1972, p. 37)
} 